\title{
NOVAS OCORRÊNCIAS DE CLADÓCEROS (BRACHIOPODA: ANOMOPODA) NO NORDESTE DO BRASIL: A IMPORTÂNCIA DE ESTUDOS EM POÇAS TEMPORÁRIAS
}

\author{
Medeiros, I.L.S. ${ }^{1,}$; Santos, F.A. ${ }^{1}$ \& Melo Júnior, M. ${ }^{1}$ \\ ${ }^{1}$ Universidade Federal Rural de Pernambuco (UFRPE), Campus Recife. Laboratório de Ecologia do Plâncton. \\ *Autor correspondente: ittalom@gmail.com
}

\begin{abstract}
Poças temporárias são sistemas de grande importância ecológica, pois fornecem serviços ecossistêmicos essenciais, garantindo o incremento e manutenção da diversidade local. Por isso, estudos nesses ecossistemas, com enfoque no levantamento e distribuição de espécies aquáticas, como o zooplâncton, são ideais para melhor compreensão da amplitude e os fatores por trás da ocorrência das espécies. O presente trabalho tem como objetivo apresentar duas novas ocorrências de cladóceros para a bacia do Atlântico Nordeste Oriental. Os espécimes foram coletados durante um levantamento da fauna planctônica, realizado em maio de 2018, em seis diferentes poças temporárias, localizadas na Estação Ecológica de Tapacurá - São Lourenço da Mata. As amostras foram obtidas com a filtragem de 10 litros de água em malha de $20 \mu \mathrm{m}$, sendo os organismos fixados com formol a $4 \%$ e identificados com o auxílio de microscópio óptico. As condições limnológicas foram mensuradas com sonda multiparâmetrica, Horiba-50. Durante as etapas de amostragem, exemplares de Moina dumontii Kotov, Elías-Gutiérrez \& Granado-Ramírez, 2005 e Chydorus nitidulus (Sars, 1901) foram coletados pela primeira vez em ambientes aquáticos continentais na Bacia do Atlântico Nordeste Oriental. A espécies $M$. dumontii, apresentou sua primeira ocorrência para a região e a segunda para o Brasil. Fêmeas partenogenéticas, efipiais e machos de $M$. dumontii foram observados em poças com mata ciliar original e presença de macrófitas (Lemna e Azolla) dominando a superfície, nas margens. As variáveis limnológicas nesses ambientes mostra baixa turbidez $(58,57 \mathrm{NTU})$, alta oxigenação $\left(5,116 \mathrm{mg} \mathrm{L}^{-1}\right)$ e grande concentração de clorofila a $(17,31 \mu \mathrm{g}$ $\left.\mathrm{L}^{-1}\right)$. Em relação a C. nitidulus, foram registradas fêmeas partenogenéticas principalmente em poças com mata ciliar reduzida, com alta turbidez (202 NTU), baixa oxigenação $\left(1,77 \mathrm{mg} \mathrm{L}^{-1}\right)$ e baixa concentração de clorofila a $(4,95 \mu \mathrm{g} \mathrm{L}-1)$. O presente estudo expande para 63 a lista de espécies de cladóceros para Pernambuco. A diversidade do zooplâncton registrada em poças temporárias ainda é pouco conhecida e deve ser examinada mais detalhadamente, principalmente para fundamentar projetos de conservação em áreas ameaçadas também em outras regiões.
\end{abstract}

Palavras-chave: Moinidae, Chydoridae, zooplâncton, distribuição, neotropical. 